\title{
UTILIZAÇÃO DE PESCADA (Macrodom ancylodon) DE BAIXO VALOR COMERCIAL NA OBTENÇÃOO DE SURIMI PARA ELABORAÇÃO DE MOLDADO SABOR CAMARÃO
}

\author{
MARIA REGINA S. PEIXOTO * \\ CONSUELO L. SOUSA * \\ ELENISE DA S. MOTA **
}

Foi utilizada "pescada gó" (Macrodon ancylodon) para a produção de surimi, o qual serviu de matéria-prima para elaboração de "moldado sabor camarão". A matéria-prima e o produto foram caracterizados mediante determinações de umidade, proteínas, cinzas, lipídios, carboidratos e valor calórico. $\mathrm{O} \mathrm{pH}$ encontrado na matéria-prima foi de 6,9, indicando o seu estado de frescor. Todas as amostras foram submetidas a análises microbiológicas (Coliformes fecais, Salmonella e Staphylococcus aureus). O rendimento do surimi foi de $23,12 \%$, obtendo-se na análise sensorial do produto aceitação de $89,6 \%$. Os resultados encontrados demonstram que o surimi pode ser empregado como matéria-prima de boa qualidade na elaboração de produtos processados a serem utilizados na alimentação humana, constituindo-se em alternativa viável para o aproveitamento do pescado de baixo valor comercial.

\section{INTRODUÇÃO}

A sobrevivência da indústria de pesca no mercado, em longo prazo, pode depender da sua capacidade para responder de imediato as exigências presentes e determinar as exigências futuras do consumidor. Além do desenvolvimento de novos tipos de produtos para atender as demandas de consumo é preciso estar atento para as novas atitudes de consumo, como por exemplo o crescente interesse por alimentos saudáveis, com alto valor nutritivo e de fácil preparo $(2,3)$.

* Professora, Universidade Federal do Pará, Centro Tecnológico, Departamento de Engenharia Química (UFPA/CT/DEQ), Belém, PA (e-mail: sousa@ufpa.br).

** Aluna, Curso de Especialização, Tecnologia de Alimentos, UFPA/CT/DEQ, Belém, PA. 
$\mathrm{Na}$ indústria pesqueira ainda existe grande desperdício, ocasionado pelas formas mecânicas de manuseio e pela deficiente estocagem do pescado a bordo, fatores que tornam o peixe inadequado para o consumo humano. Além disso, a fauna acompanhante da pesca de camarão e peixes, que se caracteriza por espécies de baixo valor comercial, é muitas vezes capturada e lançada ao mar como lixo (8), contribuindo em muito para o desperdício econômico e poluição do meio ambiente. Uma das melhores alternativas para utilização deste pescado é a produção de surimi. Pasta elaborada de músculo de peixe, em que o sabor e parte da gordura são extraídos e as proteínas miofibrilares são concentradas, apresentando baixo teor de gordura e colesterol, proteínas de alto valor biológico e sabor adaptável. Sua produção pode ser feita com praticamente qualquer espécie de pescado, o que possibilita a comercialização de espécies com baixo valor comercial $(8,15,17)$.

A produção de surimi contribui para o aproveitamento máximo dos recursos alimentares disponíveis, incluindo a fauna acompanhante. Consiste na transformação de fonte protéica de alto valor biológico, que normalmente seria destinada à alimentação animal na forma de farinha de pescado, em produtos de alto valor nutritivo e qualidade tecnológica adequada para alimentação humana $(3,6,13)$.

O consumo de surimi nos Estados Unidos vem crescendo muito nos últimos anos, bem como os investimentos em pesquisas e alternativas de uso deste produto. No Japão o surimi representa $25 \%$ do total de recursos marinhos consumidos. O desenvolvimento no Brasil de linhas de pesquisa para este tipo de produto representa, também, perspectiva de exportação $(2,18)$.

Os produtos à base de surimi são muitos e classificam-se em moldados texturizados, compostos moldados e emulsionados, destacando-se nestas classes as imitações de camarão, caranguejo, presunto e salsicha de "peixe", respectivamente $(3,6,10)$. Estes produtos são elaborados pela adição de essências e condimentos que lhes conferem odores e sabores característicos $(1,7,13)$.

A vantagem da elaboração de embutidos e moldados é que se pode utilizar a maioria dos peixes, sem levar em conta espécie e tamanho, além da pasta poder ser temperada à gosto e não apresentar sabor e textura característica do peixe $(7,13)$.

O objetivo deste trabalho foi a elaboração de métodos para a produção de surimi, mediante técnicas artesanais e utilizá-lo para preparar o produto chamado "moldado sabor camarão". Verificou-se também a aceitação do produto, além de caracterizá-lo físico-química e microbiologicamente. 


\section{MATERIAL E MÉTODOS}

\subsection{MATÉRIA-PRIMA}

Quatro amostras de "pescada gó" (Macrodon ancylodon) foram adquiridas no mercado varejista da cidade de Belém (PA), levando-se em consideração características como: cheiro, transparência dos olhos, cor da guelra, ventre roliço e carne firme, que indicam o frescor do pescado.

Após a escamação, descabeçamento e evisceração das amostras, no local de coleta, estas foram lavadas em água clorada a $5 \mathrm{ppm}$ e, em seguida, acondicionadas em caixas isotérmicas recobertas com gelo e transportadas até o Laboratório de Engenharia Química (LEQ) da Universidade Federal do Pará, sendo imediatamente processadas.

\subsection{PROCESSAMENTO DO SURIMI}

Primeiramente, os filés foram retirados e lavados com água clorada a $5 \mathrm{ppm}$ e posteriormente moídos, utilizando-se disco de $5 \mathrm{~mm}$. A massa obtida foi colocada em água clorada a $10 \stackrel{\circ}{\circ}$, na proporção de três partes para uma de massa, com leve agitação durante $5 \mathrm{~min}$, seguida de repouso para a decantação. Repetiu-se esta operação em três ciclos.

No final de cada ciclo, com auxílio de saco de algodão, foi eliminado o excesso de água. Esta operação teve a finalidade de desodorizar e retirar as proteínas sarcoplasmáticas, visando a obtenção de gel com boa elasticidade $(10,14,18)$. Após a última lavagem, o músculo foi submetido a prensagem para diminuição da umidade.

A pasta protéica obtida foi misturada com $2 \%$ de cloreto de sódio e $4 \%$ de sacarose, embalada em sacos de polietileno de $1 \mathrm{Kg}$ e conservada sob temperatura de congelamento (Figura 1).

\subsection{OBTENÇÃO DO PRODUTO MOLDADO SABOR CAMARÃO}

O surimi parcialmente descongelado em água corrente foi homogeneizado com camarão seco triturado e demais ingredientes durante cinco minutos, tempo suficiente para obtenção da consistência ideal para moldagem do produto (Tabela 1).

Após a homogeneização foi realizada moldagem manual, sendo os moldados acondicionados em bandejas de isopor esterilizadas, cobertos com filme plástico e mantidos a $-10 \stackrel{\circ}{\mathrm{C}}$ (Figura 2). 
FIGURA 1 - FLUXOGRAMA DE OBTENÇÃO DO SURIMI

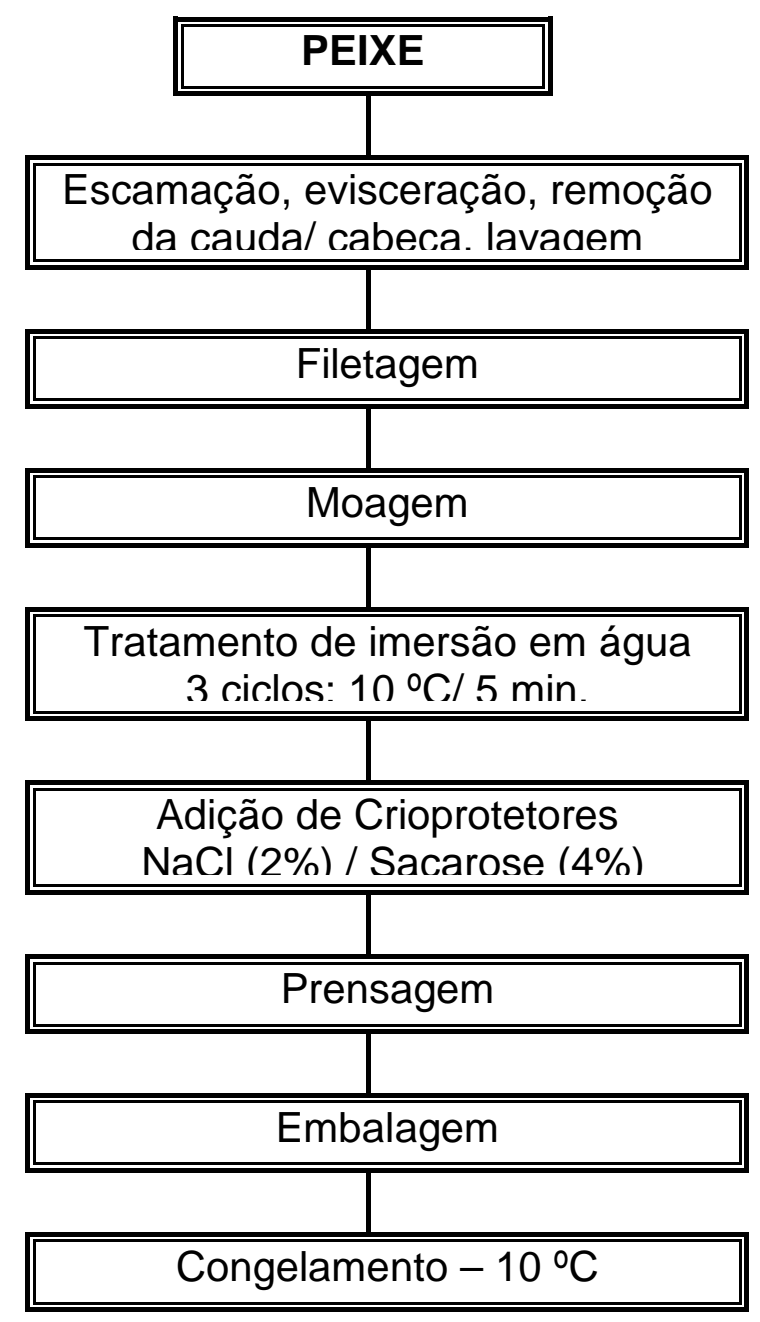

TABELA 1 - FORMULAÇÃO DO MOLDADO SABOR CAMARÃO

\begin{tabular}{l|c}
\hline C OMPONENTES & $\%$ \\
\hline "Surimi" & 90,9 \\
Camarão seco & 9,1 \\
\hline Povilho Doce & 4,0 \\
Sal & 1,0 \\
Condimento à base de camarão & 1,2 \\
Glutamato Monossódico & 0,2 \\
\hline
\end{tabular}




\section{FIGURA 2 - FLUXOGRAMA DO PROCESSAMENTO DO MOLDADO SABOR CAMARÃO}

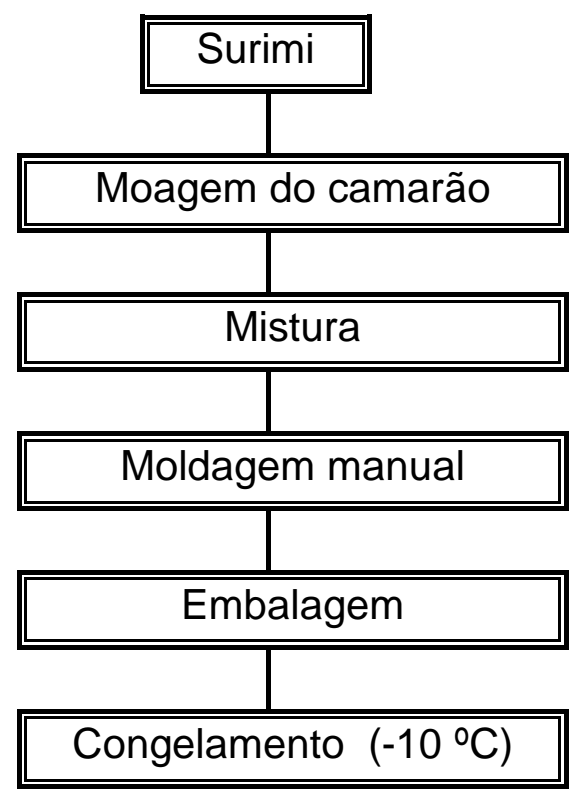

\subsection{CARACTERIZAÇÃO FÍSICO-QUÍMICA}

As determinações físico-químicas efetuadas em triplicata na matéria-prima, no surimi e no produto moldado foram: $\mathrm{pH}$, em potenciômetro digital (marca PROCYON), umidade, proteínas, lipídios e cinzas de acordo com as normas analíticas do Instituto Adolfo Lutz (11). Carboidratos e valor calórico foram determinados pelas Equações 1 e 2, respectivamente.

EQUAÇÃO 1:

$$
E=100-(A+B+C+D)
$$

A = Proteína total

$\mathrm{B}=$ Extrato-etéreo (Lipídios)

$\mathrm{C}=$ Umidade

D = Resíduo Mineral Fixo (Cinzas)
EQUAÇÃO 2:

$$
\text { VCT Kcal } / 100 \mathrm{~g}=\mathrm{C} \times 4+\mathrm{P} \times 4+\mathrm{L} \times 9
$$

\subsection{ANÁLISE MICROBIOLÓGICA}

Foram realizadas análises microbiológicas (Coliformes fecais, Salmonella e Staphylococcus aureus) na matéria-prima, no Surimi e no produto moldado 
de acordo com metodologia descrita por VANDERZANT \& SPLITTSTOESSES (19).

\subsection{ANÁLISE SENSORIAL}

Foi aplicado Teste de Aceitação no produto moldado, mediante escala hedônica estruturada de nove pontos, ancorada nos seus extremos pelos termos "gostei muitíssimo" e "não gostei muitíssimo", de acordo com metodologia descrita por PEDRERO et al. (16). Para a realização da análise $\mathrm{o}$ produto foi empanado e submetido à fritura, utilizando-se a Equação 3 para o cálculo da aceitação.

Equação 3:

$$
A=\frac{M .100 \%}{9}
$$

A = Aceitação

$\mathrm{M}=$ Média das notas obtidas

9 = Nota máxima

\subsection{AVALIAÇÃO DO RENDIMENTO DO SURIMI}

Calculou-se o rendimento pela relação entre o produto final e a quantidade inicial da matéria-prima, segundo o modelo da Equação 4 (5).

Equação 4:

$$
\eta=\left(\frac{P f}{P i}\right) .100 \%
$$

$$
\begin{aligned}
& \eta=\text { Rendimento } \\
& P f=\text { Peso final } \\
& P i=\text { Peso inicial }
\end{aligned}
$$

\section{RESULTADOS E DISCUSSÃO}

\subsection{CARACTERIZAÇÃO FÍSICO-QUÍMICA}

Os resultados da caracterização físico-química da matéria-prima estão apresentados na Tabela 2, juntamente com os resultados encontrados em análise de "pescada gó" efetuada pelo IBAMA (12). 


\section{TABELA 2 - COMPOSIC̄̃̃O FÍSICO-QUÍMICA DA MATÉRIA-PRIMA (PESCADA GÓ)}

\begin{tabular}{l|c|c}
\hline I ETERMINAÇÕES & VALORES OBTIDOS & BAMA - 1994 (12) \\
\hline $\mathrm{pH}$ & 6,9 & - \\
Umidade (\%) & 78,36 & 72,66 \\
Proteínas (\%) & 17,44 & 18,67 \\
Lipídios (\%) & 0,2 & 1,25 \\
Cinzas (\%) & 1,17 & 1,63 \\
Carboidrato (\%) & 2,83 & - \\
Valor calórico (Kcal/100 g) & 82,86 & - \\
\hline
\end{tabular}

$\mathrm{O} \mathrm{pH}$ obtido enquadrou-se no limite que indica o estado de frescor do pescado $(7,0)$, o que favorece a elasticidade do surimi, de acordo com SUZUKI (17).

Os teores de cinzas e proteínas, relatados na Tabela 2, apresentam pouca diferença dos valores citados pelo IBAMA (12), não acontecendo o mesmo com o teor de lipídios. Entretanto, segundo GEROMEL (9) pescados magros podem apresentar teores de gordura abaixo de $2 \%$.

Os resultados das análises físico-químicas do surimi e do moldado sabor camarão estão apresentados nas Tabelas 3 e 4.

\section{TABELA 3 - COMPOSIÇÃO FÍSICO-QUÍMICA DO SURIMI}

\begin{tabular}{l|c|c}
\hline I ETERMINAÇÕES & ${ }^{r}$ ALORES OBTIDOS & GOMES (1994) \\
\hline Umidade (\%) & 75,87 & 74,5 \\
Proteínas (\%) & 11,63 & 14,3 \\
Lipídios (\%) & 0,09 & 3,4 \\
Cinzas (\%) & 1,81 & 0,2 \\
Carboidratos (\%) & 10,60 & - \\
Valor calórico ( Kcal/100 g) & 89,73 & - \\
\hline
\end{tabular}

Observou-se pequena variação no teor de umidade, quando comparado ao valor encontrado por GOMES (10), porém, deve-se levar em consideração o uso de diferentes matérias-primas e técnicas empregadas para retirada da mesma nos dois ensaios. BEIRÃO (2) classifica o surimi que apresenta teor de umidade menor que $84 \%$ como produto de primeiro grau especial. 
O teor de proteínas e lipídios do surimi ficaram abaixo do valor obtido para matéria-prima (Tabela 3 ), devido a perda de proteínas sarcoplasmáticas e gordura durante o tratamento de imersão em água a $10^{\circ} \mathrm{C}$.

\section{TABELA 4 - COMPOSIÇÃO FÍSICO-QUÍMICA DO PRODUTO MOLDADO SABOR CAMARÃO}

\begin{tabular}{l|c}
\hline I ETERMINAÇÕES & VALORES OBTIDOS \\
\hline Umidade \% & 73,89 \\
Proteínas \% & 10,33 \\
Lipídios \% & 0,06 \\
Cinzas \% & 2,59 \\
Carboidratos \% & 13,13 \\
Valor calórico Kcal/100 g & 94,38 \\
\hline
\end{tabular}

Os resultados obtidos para o produto moldado apresentaram-se coerentes com os encontrados nas determinações físico-químicas efetuadas para o surimi, levando-se em consideração os métodos empregados para sua elaboração e a variedade de ingredientes utilizados.

\subsection{ANÁLISE MICROBIOLÓGICA}

$\mathrm{Na}$ Tabela 5 podem ser observados os resultados das análises microbiológicas efetuadas na matéria-prima, no surimi e no moldado sabor camarão.

\section{TABELA 5 - RESULTADO DA ANÁLISE MICROBIOLÓGIA DA "PESCADA GÓ", DO SURIMI E DO MOLDADO}

\begin{tabular}{l|c|c|c}
\hline A mostras & $\begin{array}{c}\text { Salmonella } \\
(\mathbf{2 5} \mathbf{g})\end{array}$ & $\begin{array}{c}\text { Coliforme fecal } \\
(\mathbf{N M P} / \mathbf{g})\end{array}$ & $\begin{array}{l}\text { S. aureus } \\
(\mathbf{U F C} / \mathbf{g})\end{array}$ \\
\hline Peixe & Ausência & $<3$ & Ausência \\
Surimi & Ausência & $<3$ & Ausência \\
Moldado & Ausência & 9 & Ausência \\
\hline
\end{tabular}


A Secretaria de Vigilância Sanitária (4) estabelece ausência de Salmonella em análises de pescado, pescado cru refrigerado e congelado e pescado pré-cozido, bem como no máximo $10^{2} / \mathrm{g}$ de Coliformes fecais e $10^{3} / \mathrm{g}$ no máximo de S.aureus. Não havendo padrões específicos para produtos como surimi e moldado, os mesmos foram considerados como pescado cru refrigerado e congelado. Com base na Portaria n. 451 (4) os resultado das análises microbiológicas de todas as amostras encontraram-se de acordo com os padrões estabelecidos, evidenciando processamento satisfatório. Os coliformes fecais encontrados no moldado, ainda que em pequenas quantidades, devem estar relacionados com a grande manipulação sofrida pelo produto. Assim, torna-se necessário maior atenção durante as fases de moldagem manual, para evitar a contaminação por estes microrganismos.

\subsection{ANÁLISE SENSORIAL}

O produto moldado sabor camarão obteve "muito boa" aceitação (89,6\%), sendo que o resultado pode ser melhor visualizado na Figura 3 , que demonstra a distribuição das notas em histograma. Observou-se que o moldado obteve maior percentual (40\%) para a nota 9 , indicando que os provadores gostaram "muitíssimo" do produto.

\section{FIGURA 3 - HISTOGRAMA DO TESTE DE ACEITAÇÃO}

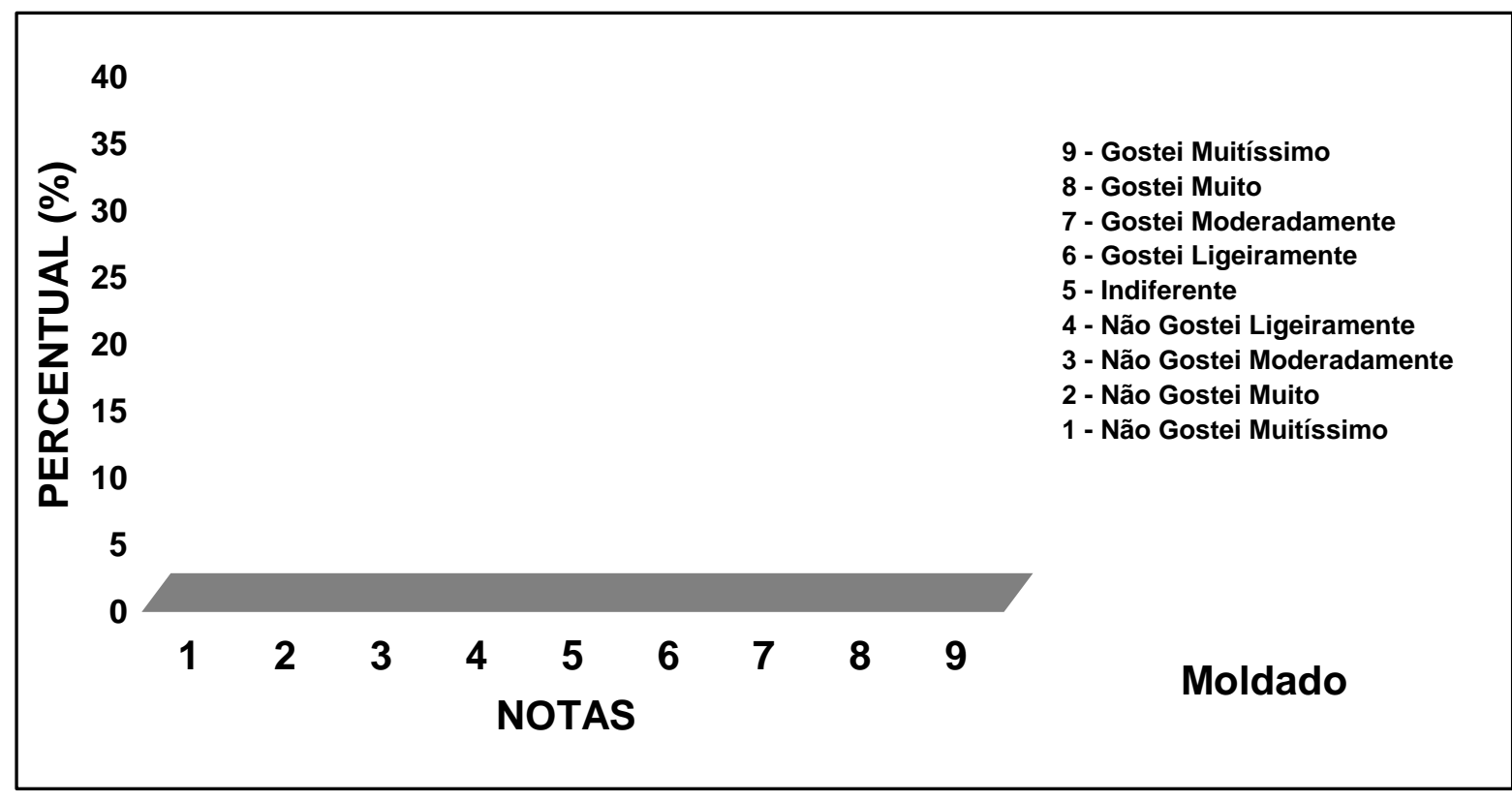




\title{
3.4 AVALIAÇÃO DO RENDIMENTO DO SURIMI
}

Comparando-se o rendimento obtido (Tabela 6) com o encontrado por GOMES (10) verifica-se que o mesmo ficou ligeiramente abaixo. Este mesmo autor cita BUCK e FAFARD (1985) e ABLETT et al. (1991) que encontraram rendimento entre 21 e $38,5 \%$, faixa em que se enquadra 0 rendimento obtido.

\section{TABELA 6 - RESULTADO DA AVALIAÇÃO DO RENDIMENTO DO SURIMI}

\author{
PRODUTO RENDIMENTO OBTIDO (\%) \\ GOMES (1994) \\ Surimi \\ 23,12 \\ $25 \%$
}

\section{CONCLUSÃO}

A matéria-prima conservou o frescor adequado para obtenção de surimi de boa qualidade, o que foi constatado pelo $\mathrm{pH}(6,9)$ e pelos resultados das análises microbiológicas.

O surimi apresentou bom rendimento $(23,12 \%)$, alto teor de proteínas miofibrilares $(11,63 \%)$ de grande valor nutritivo e baixo teor de lipídios.

O moldado sabor camarão, obtido a partir do surimi, apresentou alto teor de proteínas, baixo teor de lipídios e "muito boa" aceitação (89,6\%).

De acordo com o resultado das análises microbiológicas o produto apresentou condições higiênico-sanitárias satisfatórias.

Os resultados encontrados demonstram que o surimi pode ser empregado como matéria-prima de boa qualidade na elaboração de produtos processados a serem utilizados na alimentação humana, constituindo-se em alternativa viável para o aproveitamento do pescado de baixo valor comercial.

\section{Abstract}

"Fished gó" (Macrodon ancylodon) was utilized for the production of surimi, which served as raw material for molded flavor shrimp elaboration. The raw material and the products were characterized through determinations of humidity, proteins, ashes, lipids, carbohydrates and caloric value. The $\mathrm{pH}$ found in the raw material was of 6,9 , indicating its state of coolness. All the samples were submitted to microbiological analyses (fecal Coliforms, Salmonella and Staphylococcus aureus). The product was evaluated by sensorial analysis, being verified acceptance of $89,6 \%$. It also took place evaluation of the 
revenue of Surimi being obtained a good result $(23,12 \%)$. The results found show that surimi can be applied as raw material of good quality on the elaboration of processed products to be used in human foods, constituting a possible alternative to make good use of low commercial value fishery.

\section{REFERÊNCIAS}

1 AMANAJÁS, C.C. Contribution a la préparation de concentré protéique de poissons gras en vue de re'soudre le problème du faux-poisson de la péche de crevette su les côtes nor Brésiliennes. Toulouse, 1994. 220 p. Tese (Doutorado), Institut National Polytechnique de Toulouse.

2 BEIRÃO, L. H. Surimi: alternativa contra o desperdício de pescado. Revista Nacional da Carne, v. 17, n. 207, p 55-56, maio 1994.

3 BEIRÃO, L. H. Utilização de pescado de baixo valor comercial para produção de surimi. Revista Nacional da Carne, n. 186, p. 63-64, ago. 1992.

4 BRASIL. Ministério da Saúde. Secretaria de Vigilância Sanitária. Portaria n. 451, de 19 de setembro de 1997. Aprova os padrões microbiológicos para produtos destinados ao consumo. Diário Oficial [da] República Federativa do Brasil, Brasília, 2 jul. 1998. Seção 1, p. 2.

5 CAHILL, V.R. Princípios do processamento de carne. São Paulo: ITAL/EMBRAPA/Centro de Pesquisa e Treinamento em Tecnologia de Carne, 1980. $122 \mathrm{p}$.

6 DOUGLAS-SCHWARZE, M.; LEE, C.M. Comparison of the thermostability of Red Hake and Alaska Polock surimi during processing. Journal of Food Science, v. 53, n. 5, p. 13471351,1988 .

7 FREITAS, C. M. K. H. Embutidos de peixe: uma proposta para o aproveitamento tecnológico do produto da pesca. Belém, 1997. 110 p. Monografia (Especialização), Tecnologia do Pescado, Faculdade de Ciências Agrárias do Pará.

8 GABY, Y. C. G. Surimi: composição e manufatura. Belém, PA, 1997. 98 p. Monografia (Especialização), Tecnologia e Conservação do Pescado, Faculdade de Ciências Agrárias do Pará.

9 GEROMEL, E. J.; FORSTER, R. J. Princípios fundamentais em tecnologia de pescados. São Paulo: Fundação Tropical de Pesquisa e Tecnologia, 1982. 
10 GOMES, J. C. et al. Processamento e caracterização do surimi de peixe de água doce. Ciência e Tecnologia de Peixe de Água Doce, v. 14, n. 2, p. 226-237, jul./dez. 1994.

11 INSTITUTO ADOLFO LUTZ. Normas analíticas do Instituto Adolfo Lutz. São Paulo, 1985. v. 1.

12 IBAMA. Camarão norte e piramutaba. Brasília, 1994. (Coleção Meio-Ambiente, Série Estudos-Pesca, 9).

13 LEE, C. M. Surimi manufacturing and fabrication of surimi-based products. Food Technology, v. 42, n. 3, p. 115-124, March, 1988.

14 LEE, C. M. Surimi process technology. Food Technology, v. 38, n. 11, p. 69- 75, Nov. 1984.

15 OGAWA, M. Embutidos de peixe. In: OGAWA, M.; KOIKE, J. Manual de pesca. Fortaleza: Associação dos Engenheiros de Pesca do Estado do Ceará, 1987. 656 p.

16 PEDRERO, A. L.; PANGBORN, R.M. Evaluación sensorial de los alimentos: métodos analíticos. México: Alhambra, 1997. 346 p.

17 SUZUKI, T. Tecnologia de las proteínas de pescado y krill. Zaragoza: Acribia, 1987. $435 \mathrm{p}$.

18 TAHA, P. Estudos de viabilidade técnico-econômica da produção de surimi. Florianópolis, 1996.176 p. Dissertação (Mestrado), Engenharia de Produção, Universidade Federal de Santa Catarina.

19 VANDERZANT, C.; SPLITTSTOESSER, D. F. Compendium of methods for the microbiological examinations of food. Washington, D. C.: American Public Helth Association, 1992. 1219 p. 